\title{
Comparison between Preoperative and Postoperative Sublingual Misoprostol for Prevention of Postpartum Hemorrhage during Cesarean Section: A Randomized Clinical Trial
}

\author{
Alaa Eldin A. Youssef, Mansour A. Khalifa, Mohamed Bahaa, Ahmed M. Abbas* \\ Department of Obstetrics \& Gynecology, Faculty of Medicine, Assiut University, Assiut, Egypt \\ Email: ^bmr90@hotmail.com
}

How to cite this paper: Youssef, A.E.A., Khalifa, M.A., Bahaa, M. and Abbas, A.M. (2019) Comparison between Preoperative and Postoperative Sublingual Misoprostol for Prevention of Postpartum Hemorrhage during Cesarean Section: A Randomized Clinical Trial. Open Journal of Obstetrics and Gynecology, 9, 529-538.

https://doi.org/10.4236/ojog.2019.94052

Received: March 16, 2019

Accepted: April 25, 2019

Published: April 28, 2019

Copyright $\odot 2019$ by author(s) and Scientific Research Publishing Inc. This work is licensed under the Creative Commons Attribution International License (CC BY 4.0).

http://creativecommons.org/licenses/by/4.0/

\begin{abstract}
Background: Blood loss is one of the important complications during cesarean section (CS). Previous reports have shown that misoprostol is effective in reducing blood loss during and after CS. However, the optimum time for its administration to decrease the amount of $\mathrm{PPH}$ is still under discussion. Objective: To compare the effect of preoperative and postoperative administration of sublingual misoprostol $(400 \mu \mathrm{g})$ in reducing the amount of blood loss during and 24 hours after CS. Setting: Obstetrics and Gynecology Department, Faculty of Medicine, Assiut University, Assiut, Egypt, between January 2017 and July 2018. Study Design: A prospective, randomized clinical trial. Methods: Four-hundred thirty women fulfilling the inclusions criteria: elective lower segment CS at term ( $\geq 37$ weeks) with normal fetal heart tracing who accepted to participate in the study. Patients were divided into two groups; Patients assigned to group 1 received $400 \mu \mathrm{g}$ sublingual misoprostol immediately after urinary catheterization and before skin incision, while patients assigned to group 2 received sublingual misoprostol immediately after skin closure. The primary outcome was the estimation of intraoperative and postoperative blood loss for 24 hours. Results: There was a significant reduction in the intraoperative blood loss in group 1 compared with group 2 ( $403.51 \pm 72.99$ vs. $460.99 \pm 74.66 \mathrm{ml}$, respectively). Also, there was a significant reduction in postoperative blood loss in group 1 compared with group 2 with a statistical significance $(169.45 \pm 12.03$ vs. $195.77 \pm 13.34 \mathrm{ml}$, respectively). Postoperative hemoglobin and Hematocrit values were significantly higher in group 1 compared with group 2. Conclusions: Preoperative administration of sublingual misoprostol $(400 \mu \mathrm{g})$ during CS is better than postoperative administration as it is associated with a reduction in the amount of intraoperative and postoperative blood loss and drop in hemoglo-
\end{abstract}


bin level.

\section{Keywords}

Blood Loss, Cesarean Section, Misoprostol, Postpartum Hemorrhage

\section{Introduction}

Cesarean section (CS) is one of the most frequently performed operative interventions worldwide [1]. Cesarean section rates increase each year throughout the world. Cesarean delivery can lead to some serious maternal and fetal complications [2] including primary postpartum hemorrhage (PPH). Primary PPH is defined as a blood loss of more than $1000 \mathrm{ml}$ during the first 24 hours after delivery [3], and it is the most common cause of maternal mortality worldwide [4].

Misoprostol is a synthetic prostaglandin E1 analog, commonly used for the prevention and management of $\mathrm{PPH}$. It has potent uterotonic properties and fewer side effects at therapeutic doses [5]; it is absorbed orally, vaginally and across the mucous membranes of the rectum and oral cavity [6] [7] [8]. Misoprostol is affordable, widely available, and easily administrated via multiple routes, and has a good safety profile if properly administrated and monitored, all of which might make it the standard treatment option for PPH in low-resource settings [9]. The benefits (cervical dilatation and uterine contractions) and the adverse effects (nausea, vomiting, diarrhea, fever, and chills) are dose-dependent [10].

Hofmeyr et al. studied the pharmacokinetics of misoprostol administered by various routes. According to this study, the oral route has the most rapid uptake, but the shortest duration. The rectal route has slow uptake but prolonged duration. The buccal and sublingual routes have rapid uptake, prolonged duration and greatest total bioavailability [11].

Besides that, it can be used for termination of pregnancy in cases of missed or incomplete miscarriage [12] [13]. Also, in cases with retained placenta, it may have a role in the management of associated bleeding which mostly results from atony [14] [15]. In the field of gynecology, misoprostol could be used for induction of cervical ripening before office gynecological procedures [16] [17] [18]. This could decrease the associated pain induced by transcervical passage of instruments.

Intraoperative blood loss is one of the important complications during CS. In 2011, a systematic review that included twenty-one studies revealed that there is an increased incidence of intraoperative blood loss and blood transfusion with an increased number of cesarean deliveries [19]. Previous reports have shown that misoprostol is effective in reducing blood loss during and after cesarean delivery regardless of route of administration [20]. However, the optimum time for administration of misoprostol to decrease the amount of PPH is still under discussion. 
Therefore the current study aims to compare the effect of preoperative and postoperative administration of sublingual misoprostol $(400 \mu \mathrm{g})$ in reducing the amount of blood loss during and 24 hours after CS.

\section{Materials and Methods}

A prospective, randomized clinical trial was conducted in the emergency unit at Obstetrics and Gynecology Department, Faculty of Medicine, Assiut University, Assiut, Egypt, between January 2017 and July 2018. The study included women would undergo elective lower segment CS at term ( $\geq 37$ weeks) with normal fetal heart tracing.

Women with placenta previa, classical CS, preterm delivery, hypertensive disorders of pregnancy, bleeding tendency, previous history of $\mathrm{PPH}$, concurrent anticoagulant therapy, concurrent long-term use of steroids, fetal distress and antepartum hemorrhage were excluded from the study. The study was approved by the departmental ethics committee and by the corresponding institutional ethics committee. Written consent was obtained from all eligible women.

The eligible women were divided into two groups. A computer-generated random number table was used by an independent statistician to prepare sealed opaque envelopes containing a group assignment. Two groups of envelopes, corresponding to two study groups, were given to a third party (a nurse), who was unaware of the contents. The nurse distributed envelopes to patients, alternating between the groups. Patients assigned to group 1 received sublingual misoprostol (400 $\mu \mathrm{g}$, Misotac) immediately after urinary catheterization and before skin incision. Patients assigned to group 2 received sublingual misoprostol immediately after skin closure.

Cesarean deliveries were performed by well-trained resident doctor supervised by assistant lecturer or obstetrician consultant. The cesarean Delivery technique was the same in all recruited women. CS was performed under spinal anesthesia. The abdominal skin incision was done through a Pfannenstiel incision 2 to $3 \mathrm{~cm}$ above the symphysis pubis, with the midportion of the incision within the shaved area of the pubic hair for a length of about $10-12 \mathrm{~cm}$ was done. After the rectus fascia was opened, the rectus muscles were separated and dissected off the peritoneum which was picked up between two tissue forceps and opened longitudinally. The uterus was opened through a transverse lower segment incision. Both groups received $10 \mathrm{IU}$ oxytocin intramuscularly after fetal delivery and then $10 \mathrm{IU}$ in $500 \mathrm{ml}$ Ringer lactate solution by intravenous infusion at a rate of $125 \mathrm{~mL} /$ hour for 4 hours.

After clamping of the umbilical cord, the women received $1.5 \mathrm{gm}$ Ampicillin-Sulbactam (Ultracillin, Sedico, Egypt) and $80 \mathrm{mg}$ Garamycin (Epigent, EPICO, Egypt). Uterine incision repair was done by absorbable continuous vicryll sutures in two layers, parietal peritoneum was sutured by absorbable continuous vicryl1 sutures, rectus sheath was closed by absorbable continuous vicryl2 sutures, the subcutaneous fatty layer was closed by absorbable continuous vicryl 1 sutures, and skin was closed by vicryl2-0 by subcuticular sutures. 
All the towels were weighed before and after CS, and the weight difference was calculated, the amount of intraoperative blood loss was estimated in the suction apparatus in ml. A trained nurse was responsible for blood and amniotic fluid collection during surgery using two separate suction sets, as well as for weighing the surgical towels before and after surgery; all towels that were used were of the same size and weight, and every $1 \mathrm{gm}$ increase in weight was equated with $1-\mathrm{mL}$ blood loss. The total amount of intraoperative blood loss was calculated (blood loss in suction apparatus plus weight difference of used towels).

A second trained nurse was responsible for postoperative external blood loss measurement during the first 24 hours after surgery by weighing the soaked towels placed in the vulvar area. The postoperative blood loss was calculated (weight difference of towels placed in the vulvar area). The overall blood loss was calculated. Another blood picture was obtained 24 hours postoperative to detect changes in $\mathrm{Hb}$ level.

The primary outcome was the estimation of intraoperative and postoperative blood loss for 24 hours. Secondary outcomes included changes in hemoglobin concentration, misoprostol-induced maternal adverse effects, need to use other uterotonic drugs, need to further surgical interventions and need for blood transfusion.

\subsection{Sample Size Calculation}

The sample size was determined by using $G^{*}$ power version 3.1.9.2 for windows for Power analysis. We estimated 430 patients to be included in the study, 215 patients in each group, would be needed to show a $5 \%$ difference in a drop in hemoglobin level between the two groups with statistical power $95 \%$ and $0.05 \%$ as an alpha error.

\subsection{Statistical Analysis}

Data entry and analysis were carried out using the Statistical Package of Social Sciences for Windows (SPSS, Chicago, Illinois, USA) version 20. Quantitative variables were presented in terms of mean \pm standard deviation, and qualitative variables were expressed as frequency and percentage. Tests of significance (T-test and chi-square) were calculated. The significance level was set at a $\mathrm{p}$ value $<0.05$.

\section{Results}

Four hundred sixty-six women were approached to participate in the study. We excluded 29 cases as they did not meet the inclusion criteria and seven women refused to participate in the study as shown in the study flowchart (Figure 1).

Four-hundred thirty women were randomized to both study groups (215 in each arm). In the end, six cases were excluded from the final analysis (two women from preoperative misoprostol group and four women from postoperative misoprostol group) due to failed spinal anesthesia or early discharge before completing the follow-up. 


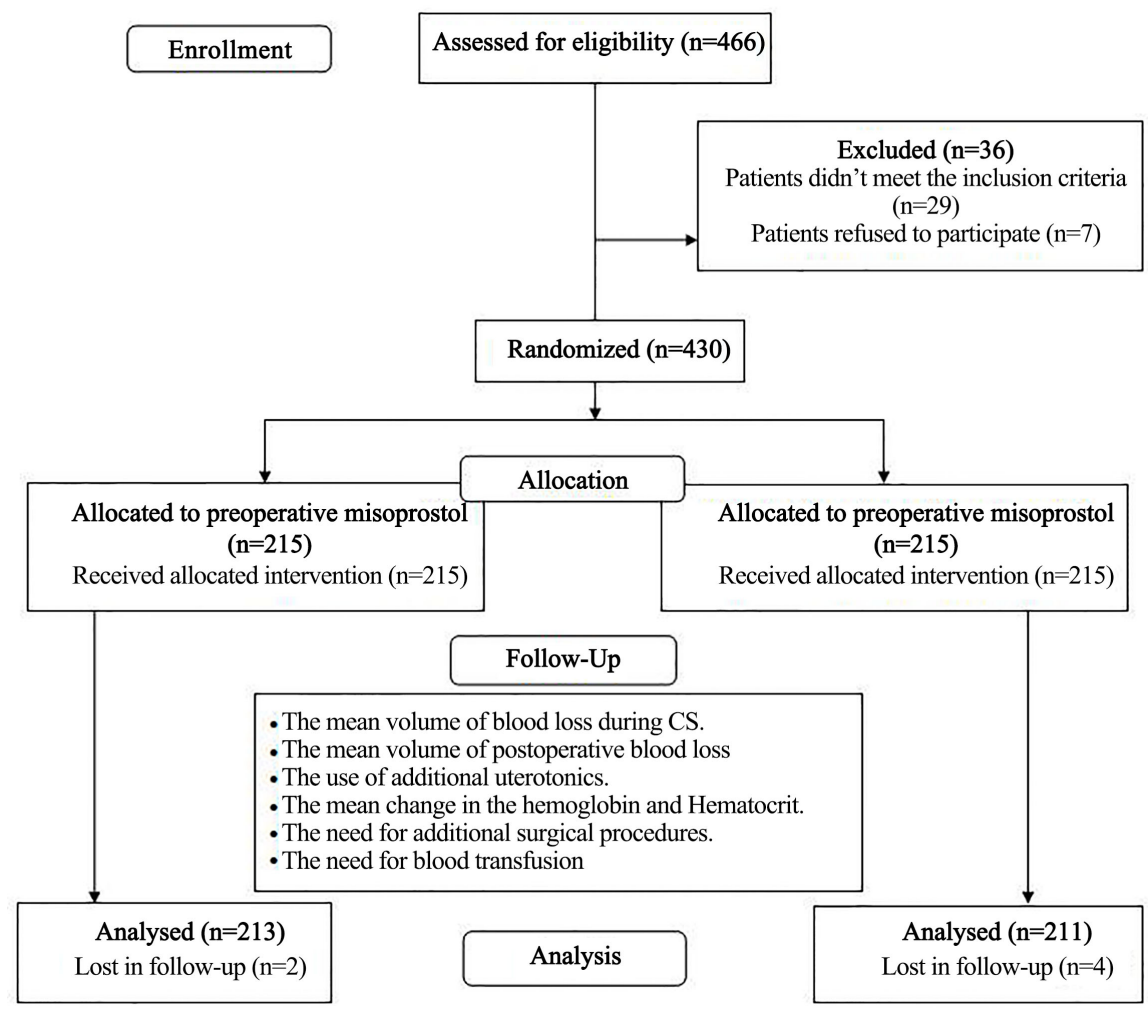

Figure 1. The study flowchart.

The baseline characteristics of both groups were quite similar with no statistically significant differences regarding age, gravidity, gestational age and number of previous CS as shown in Table 1.

There were no statistically significant differences between both groups regarding preoperative hemoglobin level and Hematocrit value $(\mathrm{p}>0.05)$. Postoperative hemoglobin and Hematocrit were significantly higher in group $1(\mathrm{p}=$ 0.04 and 0.007 respectively).

Postoperative hemoglobin was significantly lower in both groups than preoperative level ( $\mathrm{p}=0.001$ for both) as shown in Table 2. There was a significant reduction in the intraoperative blood loss in group 1 compared with group 2 ( $403.51 \pm 72.99$ vs. $460.99 \pm 74.66 \mathrm{~mL}$ respectively, $\mathrm{p}=0.001)$. The same observed in postoperative blood loss with a statistical significance (169.45 \pm 12.03 vs. $195.77 \pm 13.34 \mathrm{~mL}$ respectively, $\mathrm{p}=0.001)$. The total estimated blood loss was significantly lower in group $1(\mathrm{p}=0.001)$ as shown in Table 3 .

There was no statistically significant difference between both groups regarding the rate of intraoperative uterine atony $(\mathrm{p}=0.669)$, the need for additional oxytocin or ergometrine ( $\mathrm{p}=0.669$ and 0.502 , respectively) and need for blood transfusion $(p=0.815)$. Additionally, no significant difference was observed between both groups regarding the need for additional surgical procedures $(\mathrm{p}=$ $0.181)$, need for postoperative uterotonics $(\mathrm{p}=0.622)$, duration of surgery $(\mathrm{p}=$ $0.973)$ and duration of hospital stay $(\mathrm{p}=0.518)$ as shown in Table 4 .

Fever and chills were more frequent in group 1 than in group 2 with statisti- 
cally significant difference ( $\mathrm{p}=0.036$ and 0.002 , respectively). The rate of nausea, vomiting, and diarrhea was similar in both groups as shown in Table 5.

Table 1. The sociodemographic characteristics of the study participants.

\begin{tabular}{cccc}
\hline Variables & $\begin{array}{c}\text { Group I (preoperative misoprostol) } \\
(\mathrm{n}=213)\end{array}$ & $\begin{array}{c}\text { Group II (postoperative misoprostol) } \\
(\mathrm{n}=211)\end{array}$ & p-value \\
\hline Age (years) & $26.98 \pm 5.11$ & $27.51 \pm 0.46$ & 0.298 \\
Gravidity & $3.58 \pm 2.0$ & $3.62 \pm 1.94$ & 0.859 \\
No. of previous CS & $1.42 \pm 1.24$ & $1.40 \pm 1.33$ & 0.845 \\
Gestational age (weeks) & $38.76 \pm 1.07$ & $38.21 \pm 1.09$ & 0.320 \\
\hline
\end{tabular}

CS; cesarean section. Variables are presented as mean \pm standard deviation.

Table 2. The laboratory investigations preoperative and $24 \mathrm{~h}$ postoperative among the study participants (within the groups and inter-group comparisons).

\begin{tabular}{|c|c|c|c|c|c|c|c|c|}
\hline \multirow[t]{2}{*}{ Variables } & \multicolumn{3}{|c|}{$\begin{array}{l}\text { Group I (preoperative misoprostol) } \\
\qquad(\mathrm{n}=213)\end{array}$} & \multicolumn{3}{|c|}{$\begin{array}{l}\text { Group II (postoperative misoprostol) } \\
\qquad(\mathrm{n}=211)\end{array}$} & \multicolumn{2}{|c|}{$\begin{array}{l}\text { Inter-Group Comparisons } \\
\text { p-value }\end{array}$} \\
\hline & Preoperative & Postoperative & p-value ${ }^{\#}$ & Preoperative & Postoperative & p-value ${ }^{\#}$ & Preoperative & Postoperative \\
\hline Hemoglobin level & $11.02 \pm 1.4$ & $10.54 \pm 1.47$ & $0.001^{*}$ & $11.01 \pm 1.3$ & $10.07 \pm 1.1$ & $0.001^{*}$ & 0.944 & $0.04^{*}$ \\
\hline Hematocrit value & $33.99 \pm 3.89$ & $31.24 \pm 3.16$ & 0.06 & $33.77 \pm 3.52$ & $28.24 \pm 3.52$ & $0.02^{*}$ & 0.554 & $0.007^{*}$ \\
\hline
\end{tabular}

${ }^{\star}$ Statistical significant difference. All variables are presented as mean \pm standard deviation, ${ }^{*} \mathrm{p}$-value obtained by comparing variables using paired $\mathrm{t}$-test. ${ }^{\$}$ p-value obtained by comparing variables using Student's t-test.

Table 3. The amount of blood loss in both study groups.

\begin{tabular}{cccc}
\hline Outcomes & $\begin{array}{c}\text { Group I (preoperative misoprostol) } \\
(\mathrm{n}=213)\end{array}$ & $\begin{array}{c}\text { Group II (postoperative misoprostol) } \\
(\mathrm{n}=211)\end{array}$ & p-value \\
\hline Blood loss in towels $(\mathrm{ml})$ & $176.11 \pm 30.24$ & $195.54 \pm 26.32$ & $0.001^{*}$ \\
Blood loss in suction apparatus $(\mathrm{ml})$ & $227.39 \pm 49.25$ & $265.45 \pm 57.13$ & $0.001^{*}$ \\
Intra-operative blood loss $(\mathrm{ml})$ & $403.51 \pm 72.99$ & $460.99 \pm 74.66$ & $0.001^{*}$ \\
Post-operative vaginal bleeding $(\mathrm{ml})$ & $169.45 \pm 12.03$ & $195.77 \pm 13.34$ & $0.001^{*}$ \\
Total estimated blood loss $(\mathrm{ml})$ & $572.96 \pm 78.73$ & $656.76 \pm 82.43$ & $0.001^{*}$ \\
\hline
\end{tabular}

Variables are presented as mean and standard deviation, ${ }^{\star}$ Statistical significant difference.

Table 4. The secondary outcomes in both study groups.

\begin{tabular}{|c|c|c|c|}
\hline Outcomes & $\begin{array}{l}\text { Group I (preoperative misoprostol) } \\
\qquad(\mathrm{n}=213)\end{array}$ & $\begin{array}{l}\text { Group II (postoperative misoprostol) } \\
\qquad(\mathrm{n}=211)\end{array}$ & p-value \\
\hline $\begin{array}{l}\text { Intraoperative } \\
\text { uterine atony }\end{array}$ & $10(4.7)$ & $13(6.1)$ & 0.669 \\
\hline $\begin{array}{l}\text { Need for additional } \\
\text { intraoperative oxytocin }\end{array}$ & $10(4.7)$ & $13(6.1)$ & 0.669 \\
\hline $\begin{array}{c}\text { Need for additional } \\
\text { intraoperative ergometrine }\end{array}$ & $3(1.4)$ & $5(2.4)$ & 0.502 \\
\hline Need for blood transfusion $\$$ & $14(6.5)$ & $17(8.0)$ & 0.815 \\
\hline
\end{tabular}




\section{Continued}

\begin{tabular}{|c|c|c|c|}
\hline $\begin{array}{c}\text { Need for bilateral } \\
\text { uterine artery ligation }\end{array}$ & $2(1.0)$ & $3(1.4)$ & 0.181 \\
\hline Need for hysterectomy $y^{s}$ & 0 & 0 & ---- \\
\hline $\begin{array}{c}\text { Need for additional } \\
\text { postoperative oxytocin }\end{array}$ & $1(0.5)$ & $2(0.9)$ & 0.622 \\
\hline $\begin{array}{l}\text { Duration of surgery }{ }^{\#} \\
\text { (minutes) }\end{array}$ & $39.65 \pm 5.83$ & $39.67 \pm 6.35$ & 0.973 \\
\hline Duration of hospital stay (days) & $1.05 \pm 0.24$ & $1.04 \pm 0.19$ & 0.518 \\
\hline
\end{tabular}

${ }^{\#}$ Variables are presented as mean and standard deviation. ${ }^{\$}$ Variables are presented as frequency and percentage.

Table 5. The side effects of misoprostol in both study groups.

\begin{tabular}{cccc}
\hline Variables & $\begin{array}{c}\text { Group I (preoperative misoprostol) } \\
(\mathbf{n}=213)\end{array}$ & $\begin{array}{c}\text { Group II (postoperative misoprostol) } \\
(\mathbf{n}=\mathbf{2 1 1})\end{array}$ & $\begin{array}{c}\text { p-value } \\
\text { Fever }\end{array}$ \\
Chills & $36(16.9)$ & $22(10.4)$ & $\mathbf{0 . 0 3 6 ^ { * }}$ \\
Nausea & $64(30.0)$ & $37(17.5)$ & $\mathbf{0 . 0 0 2 ^ { * }}$ \\
Vomiting & $30(14.1)$ & $27(12.8)$ & 0.403 \\
Diarrhea & $17(8.0)$ & $9(4.3)$ & 0.081 \\
\hline
\end{tabular}

*Statistical significant difference. Variables are presented as frequency and percentage.

\section{Discussion}

In our study, we compared between the effect of preoperative and postoperative administration of sublingual misoprostol $(400 \mu \mathrm{g})$ in reducing the amount of blood loss during and 24 hours after CS to determine the optimum time for drug administration. We found that administration of sublingual misoprostol significantly reduces the intraoperative and postoperative blood loss if given preoperatively.

Lapaire et al. compared the effectiveness of oral misoprostol $(800 \mu \mathrm{g})$ and intravenous oxytocin (20 IU) in reducing blood loss in women undergoing CS. The total blood loss was $1083 \pm 920 \mathrm{ml}$ in the misoprostol group and $970 \pm 560$ $\mathrm{ml}$ in the oxytocin group $(\mathrm{p}=0.59)$ [21]. This is not coinciding with our results in which the blood loss was much less.

Ragab et al. compared misoprostol (400 $\mu \mathrm{g}$ ) given rectally before (group 1) or after (group 2) CS. The total amount of blood loss in group 2 was $844 \pm 270$. A number of patients requiring additional uterotonic drugs were 38 in group 1 and 69 in group 2. Three patients in group 2 experienced blood loss of more than $1000 \mathrm{ml}$ [22]. In contrast to our study, the total amount of blood loss in group 2 was much less than their study $(656.76 \pm 82.43 \mathrm{ml})$. A number of patients requiring additional uterotonic drugs were 13 in group 1 and 18 in group 2. None of our patients experienced blood loss of more than $1000 \mathrm{ml}$.

In Kumari et al. study, they were comparing between misoprostol vs. placebo in reduction of intraoperative and postoperative blood loss. Misoprostol was given rectally after catheter placement just before spinal anesthesia; the dose of 
misoprostol was $200 \mu \mathrm{g}$. The side effects were slightly higher in the misoprostol group (20\%) than in the placebo group (14\%) which was statistically insignificant $(p=0.25)$ [23]. In our study, fever and chills were more frequent in group 1 than in group 2 with a statistically significant difference $(\mathrm{p}=0.036$ and 0.002 , respectively).

In Owonikoko et al. compared sublingual misoprostol with IV oxytocin infusion administered after delivery of the fetus. Estimation of blood loss was only up to 4 hours after CS. Intraoperative blood loss in the oxytocin group was lower than the misoprostol group, but it was statistically insignificant $(\mathrm{p}=0.482$ ). Postoperative blood loss was significantly lower in the misoprostol group than oxytocin group ( $\mathrm{p}=0.02$ ) [24]. In our study, estimation of blood loss was up to 24 hours after CS; both intraoperative and postoperative blood loss was significantly lower in group 1 than in group $2(\mathrm{p}=0.001)$.

Chaudhuri et al. compared misoprostol and oxytocin versus oxytocin and placebo in reduction of blood loss during and after CS. Misoprostol was given sublingually immediately after delivery of the fetus, estimation of blood loss was up to 8 hours postoperative. The mean postoperative blood loss was lower in the misoprostol group than in the placebo group, but the difference was not statistically significant $(p=0.07)$ [25]. In our study, misoprostol was given sublingually immediately after spinal anesthesia in group 1 and immediately after skin closure in group 2, the estimation of blood loss was up to 24 hours postoperative. The postoperative blood loss is much lower in group 1 than in group 2 with a statistical significance $(\mathrm{p}=0.001)$.

\section{Limitations}

A potential weakness in our study was the administration of 20 IU oxytocin after delivery of the fetus in both study groups which could influence the intraoperative blood loss. Also, the study included patients with no risk for $\mathrm{PPH}$ and those at risk of PPH (multiple pregnancy, polyhydramnios, and hydrocephalus) who could benefit more from misoprostol. Finally, we did not have a placebo group to test the utility of misoprostol use. However, previous studies confirmed this point.

\section{Conclusion}

Preoperative administration of sublingual misoprostol (400 $\mu \mathrm{g})$ during CS is better than postoperative administration as it is associated with a reduction in the amount of intraoperative and postoperative blood loss and drop in hemoglobin level is less although fever and chills could still happen.

\section{Conflicts of Interest}

The authors have no conflicts of interest.

\section{References}

[1] Jacobs, D. and Hofmeyr, G. (2004) Extra-Abdominal versus Intra-Abdominal Re- 
pair of Uterine Incision at Caesarean Section. Cochrane Database of Systematic Reviews, No. 4, CD000085.

[2] Mathai, M., Hofmeyr, G.J. and Mathai, N.E. (2013) Abdominal Surgical Incisions for Caesarean Section. Cochrane Database of Systematic Reviews, No. 5, CD004453. https://doi.org/10.1002/14651858.CD004453.pub3

[3] American College of Obstetricians and Gynecologists (2006) ACOG Practice Bulletin: Clinical Management Guidelines for Obstetrician-Gynecologists Number 76, October 2006: Postpartum Hemorrhage. Obstetrics \& Gynecology, 108, 1039-1047. https://doi.org/10.1097/00006250-200610000-00046

[4] Mousa, H.A. and Alfirevic, Z. (2007) Treatment for Primary Postpartum Haemorrhage. Cochrane Database of Systematic Reviews, No. 1, CD003249.

https://doi.org/10.1002/14651858.CD003249.pub2

[5] Acharya, G., Al-Sammarai, M.T., Patel, N., Al-Habib, A. and Kiserud, T. (2001) A Randomized, Controlled Trial Comparing Effect of Oral Misoprostol and Intravenous Syntocinon on Intra-Operative Blood Loss during Cesarean Section. Acta Obstetricia et Gynecologica Scandinavica, 80, 245-250.

https://doi.org/10.1034/j.1600-0412.2001.080003245.x

[6] Tang, O.S., Schweer, H., Seyberth, H.W., Lee, W.H. and Ho, P.C. (2002) Pharmacokinetics of Different Routes of Administration of Misoprostol. Human Reproduction, 17, 332-336. https://doi.org/10.1093/humrep/17.2.332

[7] Othman, E.R., Fayez, M.F., El Aal, D.E., Mohamed, H.S., Abbas, A.M. and Ali, M.K. (2016) Sublingual Misoprostol versus Intravenous Oxytocin in Reducing Bleeding during and after Cesarean Delivery: A Randomized Clinical Trial. Taiwanese Journal of Obstetrics \& Gynecology, 55, 791-795.

https://doi.org/10.1016/j.tjog.2016.02.019

[8] Shady, N.W., Sallam, H.F., Elsayed, A.H., Abdelkader, A.M., Ali, S.S., Alanwar, A., et al. (2017) The Effect of Prophylactic Oral Tranexamic Acid plus Buccal Misoprostol on Blood Loss after Vaginal Delivery: A Randomized Controlled Trial. The Journal of Maternal-Fetal \& Neonatal Medicine, 32, 1806-1812. https://doi.org/10.1080/14767058.2017.1418316

[9] Derman, R.J., Kodkany, B.S., Goudar, S.S., Geller, S.E., Naik, V.A., Bellad, M.B., et al. (2006) Oral Misoprostol in Preventing Postpartum Hemorrhage in Resource-Poor Communities: A Randomised Controlled Trial. The Lancet, 368, 1248-1253. https://doi.org/10.1016/S0140-6736(06)69522-6

[10] Goldberg, A.B., Greenberg, M.B. and Darney, P.D. (2001) Misoprostol and Pregnancy. The New England Journal of Medicine, 344, 38-47. https://doi.org/10.1056/NEJM200101043440107

[11] Hofmeyr, G., Ferreira, S., Nikodem, V.C., Mangesi, L., Singata, M., Jafta, Z., et al. (2004) Misoprostol for Treating Postpartum Haemorrhage: A Randomized Controlled Trial. BMC Pregnancy Childbirth, 4, 16.

https://doi.org/10.1186/1471-2393-4-16

[12] Mitwaly, A.B., Abbas, A.M. and Abdellah, M.S. (2016) Intra Uterine Extra-Amniotic versus Vaginal Misoprostol for Termination of Second Trimester Miscarriage: A Randomized Controlled Trial. International Journal of Reproductive BioMedicine, 14, 643. https://doi.org/10.29252/ijrm.14.10.643

[13] Mitwaly, A.B. and Abbas, A.M. (2017) Intrauterine Extra-Amniotic Misoprostol Solution Is Effective for Termination of Second Trimester Missed Abortion: A Clinical Pilot Descriptive Study. Thai Journal of Obstetrics and Gynaecology, 25, 6-10. 
[14] Maher, M.A., Sayyed, T.M. and Elkhouly, N.I. (2017) Different Routes and Forms of Uterotonics for Treatment of Retained Placenta: A Randomized Clinical Trial. The Journal of Maternal-Fetal \& Neonatal Medicine, 30, 2179-2184. https://doi.org/10.1080/14767058.2016.1242124

[15] Abbas, A.M. (2019) Different Routes and Forms of Uterotonics for Treatment of Retained Placenta: Methodological Issues. The Journal of Maternal-Fetal \& Neonatal Medicine, 32, 1048. https://doi.org/10.1080/14767058.2017.1377176

[16] Abdellah, M.S., Abbas, A.M., Hegazy, A.M. and El-Nashar, I.M. (2017) Vaginal Misoprostol Prior to Intrauterine Device Insertion in Women Delivered Only by Elective Cesarean Section: A Randomized Double-Blind Clinical Trial. Contraception, 95, 538-543. https://doi.org/10.1016/j.contraception.2017.01.003

[17] Khalaf, M., Amin, A.F., Sayed, Z., El-Nashar, I.M. and Abbas, A.M. (2017) A Randomized Double-Blind Controlled Trial of Two Different Doses of Self-Administered Vaginal Misoprostol for Successful Copper Intrauterine Device Insertion. Middle East Fertility Society Journal, 22, 264-268. https://doi.org/10.1016/j.mefs.2017.04.002

[18] Samy, A., Abbas, A.M., Mahmoud, M., Taher, A., Awad, M.H., Hussein, M., et al. (2019) Evaluating Different Pain Lowering Medications during Intrauterine Device Insertion: A Systematic Review and Network Meta-Analysis. Fertility and Sterility, 111, 553-561.e4. https://doi.org/10.1016/j.fertnstert.2018.11.012

[19] Marshall, N., Fu, R. and Guise, J. (2011) Impact of Multiple Cesarean Deliveries on Maternal Morbidity: A Systematic Review. American Journal of Obstetrics \& Gynecology, 205, 262.e1-262.e8. https://doi.org/10.1016/j.ajog.2011.06.035

[20] Mirteimouri, M., Tara, F., Teimouri, B., Sakhavar, N. and Vaezi, A. (2013) Efficacy of Rectal Misoprostol for Prevention of Postpartum Hemorrhage. Iranian Journal of Pharmaceutical Research, 12, 469-474.

[21] Lapaire, O., Schneider, M.C., Stotz, M., Surbek, D.V., Holzgreve, W. and Hoesli, I.M. (2006) Oral Misoprostol vs. Intravenous Oxytocin in Reducing Blood Loss after Emergency Cesarean Delivery. International Journal of Gynecology \& Obstetrics, 95, 2-7. https://doi.org/10.1016/j.ijgo.2006.05.031

[22] Ragab, A., Barakat, R. and Alsammani, M.A. (2016) A Randomized Clinical Trial of Preoperative versus Postoperative Misoprostol in Elective Cesarean Delivery. International Journal of Gynecology \& Obstetrics, 132, 82-84. https://doi.org/10.1016/j.ijgo.2015.06.057

[23] Kumari, K.A., Swathi, E. and Saranu, S. (2016) Impact of Pre-Operative $200 \mu \mathrm{g}$ (P/R) per Rectal Misoprostol on Blood Loss during and after Cesarean Delivery. International Association of Infant Massage, 3, 49-58.

[24] Owonikoko, K.M., Arowojolu, A.O. and Okunlola, M.A. (2011) Effect of Sublingual Misoprostol versus Intravenous Oxytocin on Reducing Blood Loss at Cesarean Section in Nigeria: A Randomized Controlled Trial. Journal of Obstetrics and Gynaecology Research, 37, 715-721. https://doi.org/10.1111/j.1447-0756.2010.01399.x

[25] Chaudhuri, P., Mandi, S. and Mazumdar, A. (2014) Rectally Administrated Misoprostol as an Alternative to Intravenous Oxytocin Infusion for Preventing Post-Partum Hemorrhage after Cesarean Delivery. Journal of Obstetrics and Gynaecology Research, 40, 2023-2030. https://doi.org/10.1111/jog.12464 